\title{
A screening program to test and treat for Helicobacter pylori infection: Cost-utility analysis by age, sex and ethnicity
}

\author{
Andrea M. Teng ${ }^{*}$, Giorgi Kvizhinadze, Nisha Nair, Melissa McLeod, Nick Wilson and Tony Blakely
}

\begin{abstract}
Background: The World Health Organization recommends all countries consider screening for $\mathrm{H}$. pylori to prevent gastric cancer. We therefore aimed to estimate the cost-effectiveness of a H. pylori serology-based screening program in New Zealand, a country that includes population groups with relatively high gastric cancer rates.

Methods: A Markov model was developed using life-tables and morbidity data from a national burden of disease study. The modelled screening program reduced the incidence of non-cardia gastric cancer attributable to H. pylori, if infection was identified by serology screening, and for the population expected to be reached by the screening program. A health system perspective was taken and detailed individual-level costing data was used.

Results: For adults aged 25-69 years old, nation-wide screening for $H$. pylori was found to have an incremental cost of US\$196 million (95\% uncertainty interval [95\% UI]: \$182-\$211 million) with health gains of 14,200 QALYS (95\% UI: $5,100-26,300)$. Cost per QALY gained was US\$16,500 (\$7,600-\$38,400) in the total population and 17\% (6\%-29\%) of future gastric cancer cases could be averted with lifetime follow-up. A targeted screening program for Māori only (indigenous population), was more cost-effective at US\$8,000 (\$3,800-\$18,500) per QALY.

Conclusions: This modeling study found that $H$. pylori screening was likely to be cost-effective in this high-income country, particularly for the indigenous population. While further research is needed to help clarify the precise benefits, costs and adverse effects of such screening programs, there seems a reasonable case for policy-makers to give pilot programs consideration, particularly for any population groups with relatively elevated rates of gastric cancer.
\end{abstract}

Keywords: Gastric cancer, Cost-utility analysis, Screening program, Cost-effectiveness, Serology

\section{Background}

Helicobacter pylori is an important contributor to gastric cancer incidence [1]. Globally, the treatment of H. pylori has tended to focus on people presenting to medical attention with peptic ulcers and indigestion (dyspepsia). A recent Cochrane systematic review provides evidence that treating people with $H$. pylori infection reduces their subsequent risk of gastric cancer by one- third (95\% CI: 0.46-0.95) [2]. In addition to treating H. pylori symptomatic individuals, there has been international interest in using $H$. pylori testing to screen asymptomatic individuals in order to prevent gastric cancer from developing. For example, the Asia-Pacific consensus guidelines for

\footnotetext{
*Correspondence: andrea.teng@otago.ac.nz

Department of Public Health, University of Otago, Wellington, New Zealand
}

H. pylori infection recommend screening and treating H. pylori infection in communities with high incidence of gastric cancer incidence $(20+$ per 100,000 population) [3]. Targeted screening has been recommended in some high-income countries for people who are asymptomatic and at high risk, such as having an ethnicity or geographic background associated with a high risk of gastric cancer (e.g. Asia-Pacific country of origin) [4]. The International Agency for Research on Cancer (IARC) and the World Health Organization (WHO) recommends that all countries assess the current and future human and economic impacts of gastric cancer and of the potential value of prevention strategies [5]. 
In addition to other important social values (such as equity), intervention cost-effectiveness is an important consideration in the prioritization and funding of health services. Ten or more cost-effectiveness evaluations for $H$. pylori screening, such as serology testing, have been published from both high and low gastric cancer incidence countries including China, Taiwan, Singapore, United States, Canada and the United Kingdom. All evaluations found that $H$. pylori screening and treatment was cost-effective, given country-specific willingness-topay thresholds [5]. The models tended however to have important limitations [5] including: (i) not using metaanalysis effect sizes for $H$. pylori treatment $[2,6]$ (although some model estimates were similar to metaanalyses estimates [7-10] and had similar uncertainty $[7,8]$ ); (ii) all but two $[9,11]$ modelling studies were based on life-years-saved rather than quality adjusted life years (QALYs); (iii) few studies [11-13] conducted a probabilistic analysis to evaluate the uncertainty in the data modeled; (iv) harmful effects of treatment were generally not considered; and (v) there were no data on low-income countries. This paper aims to address the first four of these limitations.

New Zealand is an ideal high-income country for such a case study given the good quality national datasets that support modeling the cost-effectiveness of a $H$. pylori screening program. The age-standardized incidence of gastric cancer for New Zealand in 2011 was 8.0 for men and 4.3 per 100,000 for women and incidence in Māori was 18.6 for men and 14.9 per 100,000 for women (WHO World Standard Population, all ages). Gastric cancer demonstrates one of the greatest ethnic inequalities of any cancer site in New Zealand being 2.48 times higher for Māori (indigenous population) and 2.64 times higher for Pacific peoples compared to NZ European (averaged over 1981-2004) [14]. H. pylori infection is likely the greatest contributor to those inequalities [15].

We therefore undertook an assessment of the costeffectiveness of a $H$. pylori population screening program in New Zealand. The indigenous Māori population was selected to examine the relative cost-effectiveness of screening for a group with higher $H$. pylori infection prevalence and gastric cancer incidence. This selection was appropriate given excellent ethnicity data for Māori in New Zealand, and the New Zealand Government's treaty and ethical obligations to protect indigenous health.

\section{Methods}

We developed a Markov macrosimulation model to evaluate cost-effectiveness of a $H$. pylori screening program in New Zealand in 2011 compared with current medical practice. A total population screening program for 25-69 year olds was compared with a targeted screening program for Māori 25-69 years old.

\section{Model overview}

The Markov model consisted of states including: healthy, gastric cancer, death from gastric cancer and death from other causes (Fig. 1). We did not explicitly model states of $H$. pylori infection and pre-cancer but instead aimed to have a simple model structure and ensure that transition probabilities 'captured' different $H$. pylori prevalence in population groups.

\section{Intervention and comparator definition}

The modeled screening programs comprised a serology test to screen for H. pylori in healthy individuals, eradication treatment with antibiotics from a primary care doctor if required, a fecal antigen test of cure (retest) and second - line treatment if required. The recommended first-line eradication was triple therapy (omeprazole $20 \mathrm{mg}$, amoxicillin $1 \mathrm{~g}$ and clarithromycin $500 \mathrm{mg}$ twice daily for seven days [16]). Second-line eradication was quadruple therapy [16] and this was not followed by a retest. We assumed that all individuals testing positive would be treated.

Similar to many other cost-utility analyses [7-11, 13, 17-19], we adopted the $H$. pylori serology for the screening test in the main results because of its feasibility, acceptability and affordability. The alternative fecal antigen screening test is a test of active infection, however the test costs more than serology, requires a sample to be delivered promptly to the laboratory and requires patients to stop taking omeprazole, antibiotics and bismuth (OAC) for two to four weeks prior to the test, which is likely to be more problematic for participants. However, we present key results and uncertainty for fecal antigen-based screening in a probabilistic sensitivity analysis. Fecal antigen screening costs were adjusted to reflect differences in the laboratory cost and the fewer positive tests expected, by adopting a screening study finding from Japan, where fecal antigen had consistently $8 \%$ fewer positive tests compared to serology (56\%/61\%) [20]. Fecal antigen was selected in

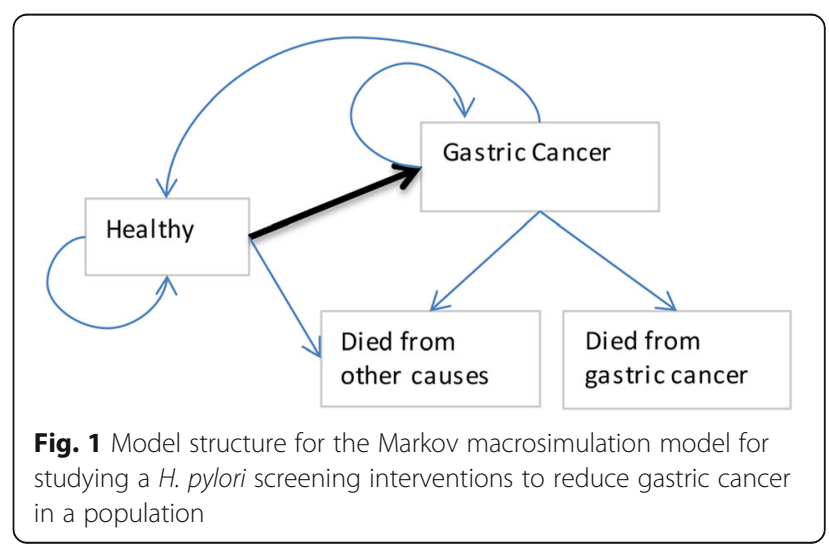


preference to urea breath test, because the former is widely used in this setting and more affordable, despite possible differences in acceptability.

\section{Input parameters}

\section{Baseline parameters}

The transition rate from 'healthy' to 'gastric cancer' was governed by cancer registry incidence rates and varied by ethnicity [21]. A $2 \%$ decline in gastric cancer incidence over time was incorporated in the model, consistent with global $[5,22]$ and New Zealand trends. Mortality rates from other causes were obtained from official New Zealand life tables [23], and the rates of gastric cancer death were derived from New Zealand cancer registry [24].

We used a modified version of a traditional qualityadjusted life-year referred to as QALY ${ }^{\mathrm{DW}}$. QALYs ${ }^{\mathrm{DW}}$ are essentially the same as traditional QALYs, except in two aspects: we use disability weights (rather than utilities) derived using pairwise comparison methods in population surveys from the Global Burden of Disease 2010 study [25], and we allow for sex and age-specific background morbidity from a New Zealand burden of disease study [26]. We use the term QALY ${ }^{\mathrm{DW}}$ in the methods sections of this paper, but default to "QALYs" elsewhere.

\section{Effect size}

A meta-analysis by Ford et al. [2] reported that the reduction in gastric cancer (referred to here as the effect size) among people with $H$. pylori infection who were treated vs not treated was $34 \%$ (RR: 0.66 , CI: $0.46-0.95$ ). The effect size is only relevant to cases of gastric cancer expected to occur in people with $H$. pylori infection that is detected by screening. We therefore applied the effect size to the number of gastric cancer cases that potentially could be prevented i.e. non-cardia gastric cancer that was attributable to $H$. pylori, for people who are likely to be screened (i.e. coverage) and where $H$. pylori is likely to be detected by the screening test (i.e. sensitivity of the screening test) (Table 1). We used these specifications:

1. The proportion of gastric cancer that was non-cardia was set to the

New Zealand distribution of non-cardia and cardia gastric cancer, excluding overlapping and undefined subtypes (2007-2011 in New Zealand, Cancer

Trends). It varied by ethnicity and sex but was generally stable by age.

2. We set $89 \%$ as the proportion of non-cardia gastric cancer attributable to $H$. pylori (population attributable fraction, PAF) [1], based on three prospective studies from Europe and Australia, where H. pylori tested by immunoblot was present in nearly $95 \%$ of non-cardia gastric cancer cases [1]. It was not possible to allow the PAF to vary by time and subgroup.

3. Coverage of screening in the main model was set according to the coverage of cardiovascular risk assessments (CVRA) for adults in New Zealand [27] adjusted for primary care enrolment, namely $81 \%$ for Mãori and 84\% for non-Mãori. A scenario analysis including 'equal coverage' by ethnicity was also run. Both CVRA and H. pylori screening are administered though primary care and involve blood tests in adults. CVRAs are a funded government target.

4. The sensitivity of screening was set at $89 \%$ for serology (and 95\% for fecal antigen in a probabilistic scenario analysis) in line with the literature $[5,28]$.

The effect size was modeled to respond to different eradication rates by ethnicity, at least partially due to differences in $H$. pylori clarithromycin resistance [29]. This was set using the relative eradication rate in New Zealand [29] compared to a pooled eradication rate from the meta-analysis (with the addition of $60 \%$ eradication for people who failed first line therapy and were retreated [16]).

In developing the model we assumed that the relative risk reduction of gastric cancer in $H$. pylori positive participants (largely dependent on one large trial in China) [2] would be similar in high and low gastric cancer incidence countries. The effect size was estimated to apply over a lifetime of follow-up, similar to other cost-utility analyses (CUAs; Table 3), and the reinfection rate in screened adults was assumed to be $0 \%$ given transmission predominantly occurs in infants and children [5]. A CUA in the UK that included a reinfection rate of $0.3 \%$ in a scenario analysis, found it had a small impact on cost-effectiveness [13].

It is plausible that the effect of treatment may be greater in younger people because they have no preexisting metaplastic changes. However, a significant effect size was evident in 55+ year olds in China [30] and there was no statistical evidence from a meta-analysis that the effect differed by presence of pre-neoplastic lesions [2]. We therefore included all ages in this analysis, assumed the effect size to be the same across age groups, and suggest future trials and meta-analyses stratify results by age wherever possible.

\section{Costs}

The downstream healthcare system costs and benefits that were incurred or averted (offset) as a result of the intervention were calculated from the health sector perspective. Costs and benefits outside the health system such as benefits to worker productivity were therefore out of scope. Costs were reported in 2011 New Zealand dollars (NZ\$) and exclude a value-added tax (GST). Selected results are 
Table 1 Summary of intervention input parameters to the Markov model for a H. pylori screening program in New Zealand

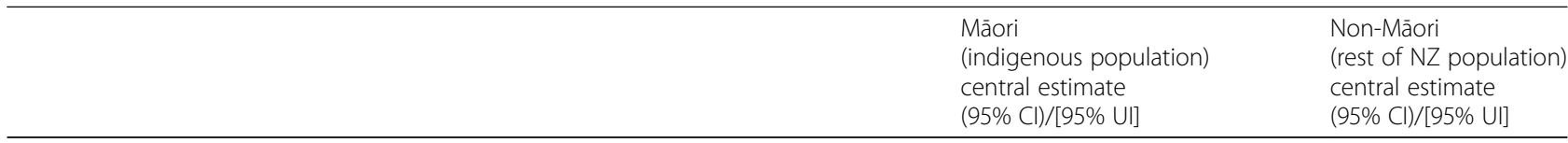

Effect size

Meta-analysis rate ratio for incidence of gastric cancer in people with

Both: $0.66(0.46-0.95)$

H. pylori infection who were treated compared to untreated ${ }^{\mathrm{b}}$

Proportion gastric cancer that was non-cardia gastric cancer (2007-11)

Men

Women

Non-cardia gastric cancer where $H$. pylori infection is detectable ${ }^{a}$

Sensitivity of the serology test $\left(S_{\text {sero }}\right)$

Expected coverage of serology test (using data from routine heart and diabetes checks in NZ adults [27])

Eradication rate reported by studies in the meta-analysis [2]

Eradication rate of OAC triple therapy in NZ, intention to treat [29] ${ }^{\text {a }}$

Eradication rate of OBTM quadruple therapy in NZ [16 ${ }^{a}$

Annual percentage decline in gastric cancer over time [5]

Screening pathway

H. pylori seroprevalence (proportion) by age-group (years) in 2011 [41]

$$
\begin{aligned}
& 25-29 \\
& 30-34 \\
& 35-39 \\
& 40-44 \\
& 45-49 \\
& 50-54 \\
& 55-59 \\
& 60-64 \\
& 65-69
\end{aligned}
$$

Risk of Clostridium difficile infection post-treatment (Brown et al., 2013)

Cost of hospitalization with moderate or severe C. difficile infection [34]

Costs of screening program (NZ, 2011)

(See Additional file 1: Table S2 for breakdown of costs and sources)

Cost per person invited (fixed health promotion, program costs)

Cost per person tested (test and result)

Cost per person with a positive test (GP visit, treatment, retest, complications)

Cost per person where eradication failed (GP visit, treatment, complications)
$0.77(0.69-0.85)$

$0.89(0.82-0.96)$

$0.45(0.41-0.49)$

$0.63(0.58-0.69)$

$0.89(0.85-1.00)$

0.89 [0.85-0.92] [28]

$0.81(0.69-0.93)^{b}$

$0.84(0.72-0.97)^{b}$

$0.73(0.71-0.75)$

$0.64(0.53-0.75)$

$0.86(0.75-0.96)$

$0.7[0.6-0.8]$

$0.02[0.01-0.03]$
$0.08[0.05-0.10]$

$0.10[0.07-0.13]$

$0.13[0.09-0.16]$

$0.15[0.11-0.20]$

$0.18[0.12-0.23]$

$0.20[0.14-0.26]$

$0.23[0.16-0.29]$

$0.25[0.18-0.33]$

$0.28[0.19-0.36]$

$0.0008[0.0004-0.0012]$

$\$ 3,856[3085-4628]$

$\$ 39.87[31.90-47.84]$

$\$ 54.66$ [43.73-65.59]

$\$ 176.70$ [141.36-212.04]

$\$ 129.85$ [103.88-155.82]

Confidence intervals (Cl) (95\%) and uncertainty ranges (also assumed to be 95\%) were used to calculate standard deviations for uncertainty intervals (Uls) using a Beta distribution for proportions and a normal distribution for scalars. There are also multiple baseline input parameters not included in this table (e.g. gastric cancer rates by sex by age by ethnic group, competing background mortality rates and health system costs for a gastric cancer patient); see text OAC omeprazole, amoxicillin and clarithromycin, OBTM omeprazole, bismuth/De-Nol, tetracycline and metronidazole, non-Māori includes Pacific, Asian, European and Other ethnic groups

${ }^{a}$ Contributes to the effect size and the screening pathway

${ }^{\mathrm{b}}$ Applied the same standard error as for the OAC eradication rate

presented in United States dollars (US\$) using the OECD 2011 purchasing power parity (2011: $1 \mathrm{NZ} \$=0.67$ US\$) [31]. A 3\% discount rate was applied to both costs and benefits. Costs of the screening program were obtained from current health system settings and adjusted to 2011 NZ\$ using the New Zealand consumer price index [32].
The cost of publicly-funded health services by age was from the New Zealand Ministry of Health database, called 'HealthTracker'. HealthTracker is a collection of linked administrative datasets of publicly funded health system events (including hospitalizations, mortality, cancer registrations, mental health and addiction service use, 
pharmaceutical and laboratory claims, primary health care enrolment, and outpatient/emergency department visits) for the entire New Zealand population with unit costs attached [33].

In the 'healthy' and 'cancer' states individuals were assigned average population health system costs and average population morbidities. Additionally, in the "gastric cancer" state individuals were assigned the excess costs of gastric cancer. The average health systems costs in the last year of life were assigned to those who died from other causes and the excess cost of gastric cancer in the last year of life was assigned to those who died from gastric cancer. More information on costing is available in the Additional file 1 and in study costing protocols [34,35].

\section{Screening program costs}

For each strata of age, sex and ethnicity, the cost per person screened was assigned based on fixed costs applied to the total population invited to be screened, costs per person tested, costs per expected rate of positive serology, and finally costs per positive retest (see Additional file 1). Costs included patient co-payments for primary care and pharmaceuticals.

Perhaps the most well-defined adverse effect of triple therapy is the risk of Clostridium difficile infection (CDI) with severe diarrhea. The cost of CDI was estimated as a 1-12 day hospital admission with severe diarrhea (using cost weights for hospital events). We set the expected rate of CDI at 80 per 100,000 people treated, according to an estimated 11 per 100,000 incidence of CDI in the community, and 2.65 times greater risk of CDI with macrolide treatment and 2.71 times greater risk with penicillin [36]. The disability weight was not included in the model because it was too small to affect QALYs ${ }^{\mathrm{DW}}$ gained given that $\mathrm{CDI}$ is rare.

\section{Analyses \\ Uncertainty analysis}

Monte Carlo simulation techniques were used for probabilistic sensitivity analysis to test the uncertainty in the model outputs. This involved selecting key input parameters probabilistically from their distributions using Excel and Ersatz software (Table 1) with 2000 simulations.

\section{Scenario analyses}

Cost-effectiveness in the total population, and for Māori and non-Māori subgroups, was examined deterministically for several scenarios including discounting, equity analyses, low coverage, 15 years of follow-up, use of levofloxacin for greater eradication success, and removing the retest step.

\section{Results}

Main analysis

The $H$. pylori screening program cost was estimated at NZ\$24,600 (\$11,300-\$57,400) (US\$16,500) per QALY gained for the total population. The targeted screening program for Māori was more cost-effective at $\$ 11,985(\$ 5,719-\$ 27,564) \quad(\mathrm{US} \$ 8,030)$ per QALY gained.

Compared to current practice, the total net cost of a one-off total population $H$. pylori screening program for 25-69 year olds (with lifetime follow-up for downstream health system costs) was \$293 million (95\% uncertainty interval [UI]: \$272-\$314, probabilistic model, discount rate 3\%) (US\$196 million) (Table 2). The net cost was made up of \$294 million (\$282-\$307) in intervention costs, and $\$ 1.5$ million ( $\$ 23-\$ 26)$ due to downstream future health system cost savings from reduced gastric cancer incidence and associated treatment costs. In comparison, a targeted $H$. pylori screening program (for Māori only) had a net cost of a \$41 million (\$35-\$46) (US\$27 million).

The health gain from the population screening program was estimated at 14,200 QALYs (95\% UI: 5100-26,300) over the cohort's lifetime. This corresponds to 3660 (1250-4430) fewer cases of gastric cancer, 2430 (830$4430)$ averted deaths from gastric cancer, and a $17 \%$ $(6 \%-29 \%)$ reduction in the expected future gastric cancer cases and deaths. The health gains for Māori were greater per person with a $22 \%(7 \%-39 \%)$ reduction in the expected Māori gastric cancer incidence and mortality.

For non-Māori, the cost per QALY was over twice that for Māori at $\$ 29,600$ per QALY gained $(\$ 13,400-\$ 69,800)$ (US\$19,900). Within the non-Māori population there was marked ethnic heterogeneity, with $15 \%$ who were Asian and 7\% who were Pacific (2013 census, 25-69 years old). Pacific people have greater gastric cancer rates than European Other peoples.

Variation in cost-effectiveness by age was explored for Māori and non-Māori subgroups (Fig. 2). Costeffectiveness for Māori was greatest in the 45-49 year old age group and for non-Māori in the 60-64 age group, likely due to relatively higher Māori rates of gastric cancer at younger ages.

Compared to current practice, the fecal antigen test was less cost-effective (ICER of $\$ 29,000$ UI: $\$ 13,600$ $\$ 69,200$ or $\$$ US 19,400$)$ than serology-based screening $(\$ 24,600)$ (Table 2, Fig. 3). More specifically, the potential QALYs gained with fecal antigen testing were $7.5 \%$ greater $(15,300$ vs 14,200 QALYs $)$ but the cost was $26 \%$ greater ( $\$ 369$ million vs $\$ 293$ million). The incremental cost-effectiveness of fecal antigen compared to serology testing was $\$ 71,700$ per QALY gained. 
Table 2 Incremental costs, QALYs gained and ICERs for the total New Zealand adult population including a subset of the population with high risk of gastric cancer (Māori), comparing serology and fecal antigen as the screening test, in 2011 with lifetime follow-up of participants

\begin{tabular}{|c|c|c|c|}
\hline Model output & $\begin{array}{l}\text { Total population } \\
25-69 \text { yo }\end{array}$ & $\begin{array}{l}\text { Māori } \\
\text { 25-69 yo }\end{array}$ & $\begin{array}{l}\text { Non-Māori } \\
\text { 25-69 yo }\end{array}$ \\
\hline \multicolumn{4}{|l|}{ Serology based screening } \\
\hline \multicolumn{4}{|l|}{ Men and women } \\
\hline Number cases of gastric cancer averted & $3658(1252-4425)$ & $1007(342-1828)$ & $2650(905-4837)$ \\
\hline Percentage cases of gastric cancer averted & $16.5 \%(5.6 \%-29.4 \%)$ & $21.6 \%(7.4 \%-38.6 \%)$ & $15.2 \%(5.2 \%-27 \%)$ \\
\hline Number of gastric cancer deaths averted & $2434(834-4425)$ & $714(242-1293)$ & $1720(588-3141)$ \\
\hline Percentage gastric cancer deaths averted & $16.6 \%(5.7 \%-29.5 \%)$ & $21.6 \%(7.3 \%-38.6 \%)$ & $15.2 \%(5.2 \%-27 \%)$ \\
\hline Total net incremental cost (NZ\$ million) & $\$ 293(\$ 272-\$ 314)$ & $\$ 41(\$ 35-\$ 46)$ & $\$ 252(\$ 233-\$ 272)$ \\
\hline Total intervention cost (NZ\$ million) & $\$ 294(\$ 282-\$ 307)$ & $\$ 41(\$ 38-\$ 45)$ & $\$ 253(\$ 242-\$ 264)$ \\
\hline Total cost offsets (NZ\$ million) & $-\$ 1.5(-\$ 26.2-\$ 22.9)$ & $-\$ 0.61(-\$ 7.35-\$ 6.21)$ & $-\$ 0.89(\$-22.7-\$ 21.7)$ \\
\hline Total QALYs gained & $14,200(5100-26,300)$ & $4000(1400-7400)$ & $10,200(3653-18974)$ \\
\hline Incremental net cost per participant (NZ\$) & $\$ 119(\$ 111-\$ 128)$ & $\$ 137(\$ 117-\$ 158)$ & $\$ 117(\$ 108-\$ 126)$ \\
\hline Incremental QALYs gained per participant & $0.0058(0.0020-0.0107)$ & $0.0137(0.0047-0.0252)$ & $0.0047(0.0016-0.0087)$ \\
\hline ICER (NZ\$ per QALY gained) & $\$ 24,600(\$ 11,300-\$ 57,400)$ & $\$ 12,000(\$ 5700-\$ 27,600)$ & $\$ 29,600(\$ 13,400-\$ 69,800)$ \\
\hline \multicolumn{4}{|l|}{ Men } \\
\hline Incremental cost per participant (NZ\$) & $\$ 123(\$ 113-\$ 134)$ & $\$ 147(\$ 123-\$ 173)$ & $\$ 120(\$ 110-\$ 131)$ \\
\hline Incremental QALYs gained per participant & $0.0071(0.0024-0.0131)$ & $0.0158(0.0055-0.0293)$ & $0.0059(0.0020-0.0110)$ \\
\hline ICER (NZ\$ per QALY gained) & $\$ 20,800(\$ 9800-\$ 47,900)$ & $\$ 11,000(\$ 5600-\$ 24,300)$ & $\$ 24,300(\$ 11,300-\$ 57,100)$ \\
\hline \multicolumn{4}{|l|}{ Women } \\
\hline Incremental cost per participant (NZ\$) & $\$ 116(\$ 108-\$ 124)$ & $\$ 129(\$ 110-\$ 148)$ & $\$ 114(\$ 105-\$ 123)$ \\
\hline Incremental QALYs gained per participant & $0.0046(0.0016-0.0085)$ & $0.0118(0.0040-0.0217)$ & $0.0036(0.0012-0.0067)$ \\
\hline ICER (NZ\$ per QALY gained) & $\$ 30,200(\$ 13,400-\$ 71,400)$ & $\$ 13,200(\$ 5900-\$ 31,300)$ & $\$ 38,000(\$ 16,800-\$ 89,900)$ \\
\hline \multicolumn{4}{|l|}{ Fecal antigen based screening } \\
\hline \multicolumn{4}{|l|}{ Men and women } \\
\hline Total incremental cost (NZ\$ million) & $\$ 369(\$ 350-\$ 389)$ & $\$ 49(\$ 44-\$ 55)$ & $\$ 320(\$ 301-\$ 339)$ \\
\hline Total QALYs gained & $15,300(5400-27,700)$ & $4200(1500-7600)$ & $11,000(3830-20,200)$ \\
\hline Incremental cost per participant (NZ\$) & $\$ 150(\$ 142-\$ 158)$ & \$164 (\$147-\$182) & $\$ 148(\$ 139-\$ 156)$ \\
\hline Incremental QALYs gained per participant & $0.0061(0.0022-0.0111)$ & $0.0142(0.0051-0.0259)$ & $0.0050(0.0018-0.0092)$ \\
\hline ICER (NZ\$ per QALY) & $\$ 29,000(\$ 13,600-\$ 65,900)$ & $\$ 13,700(\$ 6700-\$ 30,500)$ & $\$ 34,900(\$ 16,300-\$ 79,100)$ \\
\hline
\end{tabular}

Central estimates are the mean from the probabilistic sensitivity analysis Monte Carlo simulations and the brackets indicate the $95 \%$ uncertainty intervals $Q A L Y$ quality-adjusted life year with disability weights, ICER incremental cost-effectiveness ratio

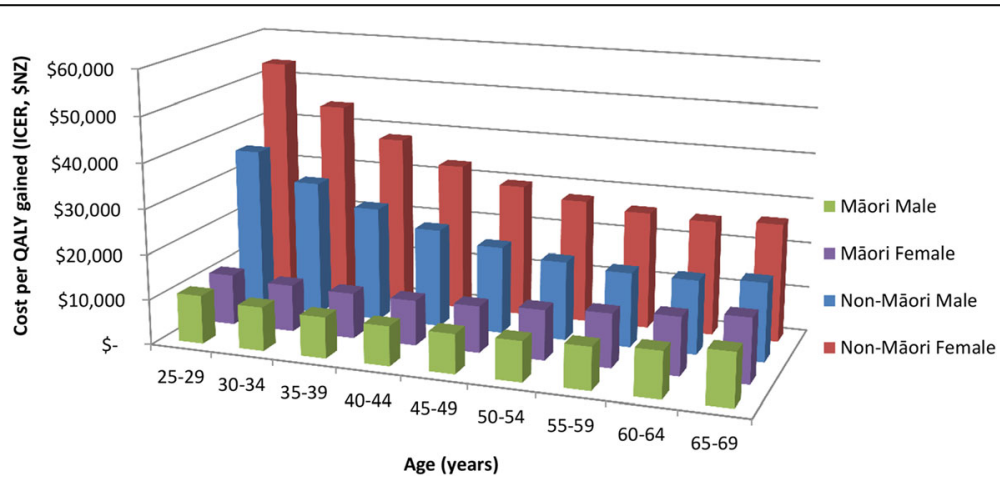

Fig. 2 Modeled cost-effectiveness of a H. pylori screening program in New Zealand by ethnicity, sex and age for the 25-69 year old population in 2011, expected value (deterministic analysis), NZ\$2011. *See supporting documents for values on this graph 


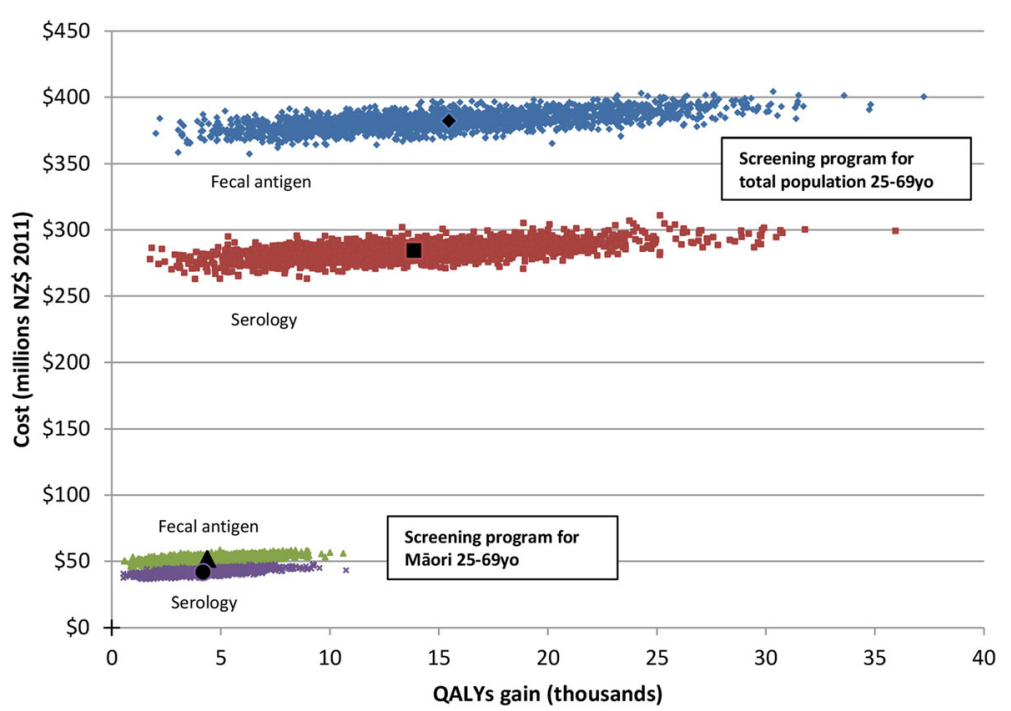

Fig. 3 Incremental costs and QALYs gained from a H. pylori screening program for Māori and the total population, comparing serology versus fecal antigen screening tests

\section{Uncertainty analysis}

Probabilistic sensitivity analysis demonstrated that at a willingness-to-pay of NZ\$45,000 per QALY, there was greater than $99 \%$ probability that a serology-based screening program for Māori men and women would be costeffective. For non-Māori men and women the probability was $94 \%$ and $77 \%$ respectively. The greatest contributor to uncertainty in the model was the effect size of $H$. pylori eradication ( $R R$ 0.66, 95\% CI: 0.46-0.95) [2]. At the extremes of the likely effect size, the cost-effectiveness of a screening program for the total population was between $\$ 12,000$ and $\$ 58,200$ per QALY gained.

\section{Scenario analyses}

Given the higher background mortality and morbidity for Māori, a gastric cancer death prevented among Māori typically achieves less health gain than a gastric cancer death prevented among non-Māori (Table 3). Therefore, we ran an 'equity analysis' where the Māori analyses were rerun with non-Māori background mortality and morbidity rates. This resulted in a $36 \%$ increase in QALYs (Table 3). In an equal coverage scenario Māori analyses were rerun with non-Māori coverage, resulting in $4 \%$ greater QALY gains for Māori. When analyses were rerun with low screening coverage adopting participation rates from the first year of a colorectal screening pilot program in one New Zealand health district (Waitemata), the QALY gains were 40\% less for Māori and 30\% less for total population.

The screening program was considerably less costeffective when the treatment effect was applied for a limited follow-up period of 15 years (ICER was $73 \%$ greater; the maximum follow-up in the most relevant meta-analysis was 15 years). Discounting (costs and benefits) had a large impact on cost-effectiveness (particularly on QALYs) reducing the ICER by $50 \%$ with no discounting; and increasing the ICER by $90 \%$ for $6 \%$ discounting. Substituting a lower screening coverage in the model (45\% for Māori and 58\% for non-Māori) caused the ICER to increase by $19 \%$ (Table 3 ).

\section{Discussion}

\section{Main findings and interpretation}

In this analysis from a high income country, the costeffectiveness of targeted screening in a high gastric cancer incidence group (Māori ICER \$12,000, UI $\$ 5,700-\$ 27,600)$ was more favorable than for the total population (ICER $\$ 24,600$, UI $\$ 11,300-\$ 57,400$ ). These findings are analogous to US findings where costeffectiveness of screening was better for Japanese American and African American participants [8, 17].

Our results for the non-Māori group (ICER of $\mathrm{NZ} \$ 24,700$, expected deterministic result, Table 3) include populations with low and high gastric cancer rates (such as Pacific peoples). Whilst we did not have data for a full ethnicity-disaggregated model, if we assume that the intervention costs are distributed pro-rata by population counts, and that the health gain is distributed proportional to gastric cancer incidence (2007-2011), then we roughly estimate that the cost-effectiveness would be $\$ 8,300$ for Pacific (76\% less than non-Māori altogether), $\$ 29,000$ for Asian and $\$ 28,800$ for European/Other (both the later were $17 \%$ greater than non-Māori aggregated). These estimates are very approximate however and do not allow for 
Table 3 Scenario analyses and their impact on health gain, health system costs, and incremental cost-effectiveness ratios per person screened, New Zealand dollars 2011

\begin{tabular}{|c|c|c|c|c|c|c|c|c|c|}
\hline & \multicolumn{3}{|c|}{ Incremental costs (NZ\$) } & \multicolumn{3}{|c|}{ Incremental QALYs gained } & \multicolumn{3}{|c|}{ Incremental cost-effectiveness ratio } \\
\hline & Total & Māori & Non-Māori & Total & Māori & Non-Māori & Total & Māori & Non-Māori \\
\hline Main model $^{a}$ & $\$ 119$ & $\$ 138$ & $\$ 117$ & 0.006 & 0.014 & 0.005 & $\$ 20,600$ & $\$ 10,100$ & $\$ 24,700$ \\
\hline $\begin{array}{l}\text { Equity analysis_equal life expectancy and background } \\
\text { morbidity for Māori and non-Māori }\end{array}$ & $\$ 121$ & $\$ 155$ & $\$ 117$ & 0.006 & 0.019 & 0.005 & $\$ 18,800$ & $\$ 8,200$ & $\$ 24,700$ \\
\hline $\begin{array}{l}\text { Equal coverage-coverage in Māori was set to the same } \\
\text { as non-Māori }(84 \%)\end{array}$ & $\$ 120$ & $\$ 143$ & $\$ 117$ & 0.006 & 0.014 & 0.005 & $\$ 20,400$ & $\$ 10,000$ & $\$ 24,700$ \\
\hline $\begin{array}{l}\text { Low coverage-coverage in Māori of } 45 \% \text { and non-Māori } \\
\text { of } 58 \% \text { akin to a NZ colorectal screening pilot }\end{array}$ & $\$ 93$ & $\$ 95$ & $\$ 93$ & 0.004 & 0.008 & 0.003 & $\$ 24,500$ & $\$ 12,400$ & $\$ 28,400$ \\
\hline $\begin{array}{l}\text { Equal eradication-triple therapy was increased to be } 95 \% \\
\text { effective (e.g. levofloxacin) }\end{array}$ & $\$ 118$ & $\$ 132$ & $\$ 116$ & 0.006 & 0.015 & 0.005 & $\$ 19,600$ & $\$ 8,900$ & $\$ 24,200$ \\
\hline No retest to ensure effective eradication & $\$ 101$ & $\$ 107$ & $\$ 100$ & 0.005 & 0.010 & 0.004 & $\$ 20,600$ & $\$ 10,900$ & $\$ 23,600$ \\
\hline Follow-up for 15 years (rather than over a lifetime) & $\$ 118$ & $\$ 132$ & $\$ 116$ & 0.003 & 0.008 & 0.003 & $\$ 35,600$ & $\$ 16,000$ & $\$ 44,000$ \\
\hline $\begin{array}{l}\text { The effect size in the youngest age groups is greater } \\
(<40 \text { yo, RR of } 0.50)\end{array}$ & $\$ 119$ & $\$ 139$ & $\$ 117$ & 0.006 & 0.016 & 0.005 & $\$ 18,400$ & $\$ 8,700$ & $\$ 22,500$ \\
\hline $\begin{array}{l}\text { The complication rate for CDI was increased from } \\
80 \text { to } 800 \text { per } 100,000\end{array}$ & $\$ 124$ & $\$ 146$ & $\$ 121$ & 0.006 & 0.014 & 0.005 & $\$ 21,400$ & $\$ 10,700$ & $\$ 25,600$ \\
\hline 6\% discounting QALYs and costs & $\$ 112$ & $\$ 118$ & $\$ 111$ & 0.003 & 0.007 & 0.002 & $\$ 39,200$ & $\$ 17,300$ & $\$ 48,200$ \\
\hline $0 \%$ discounting QALYs and costs & $\$ 151$ & $\$ 225$ & $\$ 141$ & 0.015 & 0.034 & 0.012 & $\$ 10,300$ & $\$ 6,600$ & $\$ 11,700$ \\
\hline No unrelated health system costs & $\$ 82$ & $\$ 52$ & $\$ 86$ & 0.006 & 0.014 & 0.005 & $\$ 14,200$ & $\$ 3,800$ & $\$ 18,300$ \\
\hline No pYLDs (background morbidity) & $\$ 119$ & $\$ 138$ & $\$ 117$ & 0.008 & 0.021 & 0.007 & $\$ 14,300$ & $\$ 6,700$ & $\$ 17,500$ \\
\hline
\end{tabular}

Deterministic results were used in the sensitivity analysis for efficiency and differ slightly from probabilistic results

${ }^{a}$ Main model includes 3\% discounting of both QALYs and costs

different age structures, different background mortality and morbidity rates, and heterogeneity within the Asian group. At this level of cost-effectiveness for European/ Other the uncertainty in treatment effect size and differences in cost-effectiveness by age and sex become particularly relevant to decision makers. We conclude that $H$. pylori screening is probably of borderline cost effectiveness for European/Other, but probably cost-effective for Pacific people as well as Mãori.

Variation in results by age and sex reflect the epidemiology of non-cardia gastric cancer. The intervention was particularly more cost-effective in younger Māori adults (45-49 year olds). Among Māori cost-effectiveness was similar in men and women, consistent with findings from a high risk region of China [19]. In non-Māori, cost-effectiveness peaked in participants aged 60-64 years old similar to studies in the UK [13] and US [7]; and $H$. pylori screening was more cost-effective in men, similar to US findings [17].

Serology based screening was more cost-effective than fecal antigen based screening (Fig. 3). The incremental cost effectiveness of moving from serology to the fecal antigen test was $\$ 71,700$ per QALY gained. Although the fecal antigen test has a preferable sensitivity (95\% vs $89 \%$ ) and is likely to result in greater health gains, the cost of the test was problematic (fecal antigen test cost was $\$ 65.20$ vs $\$ 30.68$ for serology). Reduction in the cost of fecal antigen testing would shift the balance towards making fecal antigen based screening more cost-effective than serology. The fecal antigen test is widely used in many high-income countries, and there may be potential to introduce it in combination within a country's national colorectal screening program (if differences in stool sample requirements can be addressed). Fecal antigen may however adversely impact on screening uptake given likely participant dislike of dealing with fecal material. Conversely, $H$. pylori serology could be added onto existing blood test requests in primary care as part of the routine screening for other conditions (such as diabetes and cardiovascular risk in the New Zealand case).

\section{Strengths and limitations}

The key strengths of this CUA are the adoption of a recent meta-analysis effect size for $H$. pylori eradication [2], presenting incremental costs per QALY gained, using probabilistic sensitivity analysis, and allowing for adverse effects of treatment costs (CDI). Our input variables included high quality New Zealand ethnicity, cancer registration and cost data. Meta-analysis results from high risk populations [2] were shaped to fit the New Zealand context by taking into account differences in non-cardia gastric cancer incidence, the PAF for $H$. pylori and gastric cancer [1], New Zealand eradication rates for $H$. pylori treatment [29], and the declining incidence of 
gastric cancer. We compared results by age, sex and ethnicity including for a population with relatively high rates of gastric cancer (Māori).

Nevertheless, the modeled benefits of our screening program are likely to be underestimated as we did not have the primary care data to include the health gains and cost reduction benefits from reduced dyspepsia and peptic ulcers attributable to $H$. pylori infection in this context. However, screening studies in the UK have demonstrated a $25 \%$ reduction in dyspepsia after two years of follow-up, with a mean saving of dyspepsiarelated costs of US\$117 per person $(\$ 11-\$ 220)$ in the 10 years after eradication therapy [37]. If this cost-saving from dyspepsia was the same in the New Zealand context, cost-effectiveness may be greater in our model. For example, if we used UK dyspepsia-related cost-savings, and subtracted these from the model's costs in 45-49 year olds seropositive for $H$. pylori over a ten year time line, this would reduce the ICER by an estimated $24 \%$ in Māori and 20\% in European/Other, even when not considering the likely QALY gain from dyspepsia relief (see Additional file 1: Table S8 for this calculation). Furthermore, other than CDI, we were unable to account for potential harms from $H$. pylori eradication treatment however adverse effects are often rare and inclusion is unlikely to influence our findings. Similarly, we did not account for any increased anxiety among those screened and told that they have $H$. pylori infection (or the reassurance value when told that they are free of infection).

This CUA was based on $H$. pylori prevalence and gastric cancer incidence in New Zealand for 2011 in all ages from 25 to 69 years. Cost-effectiveness may gradually decrease over time as $H$. pylori prevalence and gastric cancer incidence decline. It will take several decades however for the current high risk birth cohorts to be replaced by younger cohorts at low risk of $H$. pylori infection. H. pylori screening in populations with high gastric cancer incidence such as Māori appears likely to remain cost-effective for some decades into the future. Cost-effectiveness also depends on which age group is screened.

Furthermore, positive serology does not represent an active infection and some participants are likely to be treated without having $H$. pylori in their stomach. This could be remedied somewhat by using a fecal antigen test instead (as modelled) or the more expensive options of a urea breath test or a two-way diagnostic procedure. The latter would have a greater chance of losing people over two steps. Also if participants are not tested after a second therapeutic attempt a small proportion (34\%) may still have H. pylori infection. To avoid falsely reassuring treated individuals, information materials should state that treatment is not $100 \%$ effective and if they get gastric symptoms in the future they should consult their doctor.

\section{Practice, policy and research}

The WHO recommends that countries should consider piloting $H$. pylori screening to evaluate its impact on gastric cancer, all-cause mortality and potential adverse effects [5]. Given current evidence, our results indicate that screening and treating definable ethnic groups with a high risk of developing gastric cancer is likely to be the most cost-effective approach in high-income country settings. Screening may also be cost-effective in populations with low incidence of gastric cancer but more evidence is probably needed to establish more precise estimates of screening benefits and costs by age, sex and risk status.

There are many other factors that should be considered before the introduction of screening programs [38]. More information is required about the balance of harms and benefits of screening, the acceptability and feasibility of $H$. pylori infection screening tests, the capacity of the health care system particularly primary care, and potential ethical issues about identifying infection and being unable to treat it in some cases. Policy-makers would also need to consider the relative cost-effectiveness and potential equity gains of alternative interventions in high-income countries such as tobacco control, obesity control and other screening programs (for example colorectal cancer, chronic kidney disease and lung cancer in ex-smokers).

Trials of population based $H$. pylori screening in participants as young as 25 years and up to 69 years, are under way in Linqu Country, China; United Kingdom; Matsu Islands in Taiwan; Korea and another is planned for Latvia, Belarus and the Russian Federation [39]. Emerging evidence should be actively monitored to clarify the potential adverse effects of $H$. pylori screening and treatment (such as all-cause mortality outcomes from screening trials), and the most effective models of implementation. Potential adverse effects from $H$. pylori treatment require further evaluation since confounding is a likely contributor to inverse associations demonstrated between H. pylori infection and esophageal cancer, asthma, ischemic heart disease, colon cancer and antibiotic resistance [40]. Nevertheless, given what is known to date it would seem reasonable for policy-makers in high-income countries to start exploring the option of pilot screening programs for $H$. pylori, especially in population groups with relatively high rates of gastric cancer.

\section{Conclusions}

This CUA modeling study found that a $H$. pylori screening program was cost-effective in this high-income country setting for the indigenous Māori population (and likely by extension to Pacific peoples). The program was of likely borderline cost-effectiveness for the European/Other population. A screening program may therefore help to address the existing inequalities in the burden of gastric 
cancer. While further research will help clarify the precise benefits, costs and adverse effects of such screening programs, there seems a reasonable case for policy-makers to give consideration to establishing pilot programs now, particularly for any population groups with relatively elevated rates of gastric cancer.

\section{Additional file}

Additional file 1: Supplemental Material: Further information on the methods and inputs. (DOCX $122 \mathrm{~kb}$ )

\section{Abbreviations}

CDI: Clostridium difficile infection; CUA: Cost-utility analysis; CVRA: Cardiovascular Risk Assessment; GST: Goods and services tax (a value added tax); $H$. pylori: Helicobacter pylori; ICER: Incremental cost-effectiveness ratio; OECD: Organisation for economic co-operation and development; QALYDW, QALY: Modified quality-adjusted life-year; RR: Rate ratio; WHO: World Health Organization

\section{Acknowledgements}

Thank you to Dr Alan Fraser and other New Zealand colleagues in primary care and community laboratories for the input into the screening pathway.

\section{Funding}

This work was part of the $\mathrm{BODE}^{3}$ Programme which is supported by the Health Research Council of New Zealand (10/248). The funder had no role in study design, data collection and analysis, decision to publish, or preparation of the manuscript.

\section{Availability of data and materials}

Please see the Additional file for more detail on the methods and results from our model.

A H. pylori calculator based on this model can be used for cost-effectiveness evaluation of $H$. pylori screening using different input parameters. It is available in Excel and can be requested from the authors. A simplified cost-effectiveness calculator is also available on our website for estimating the cost effectiveness of cancer treatment and prevention interventions: http://www.otago.ac.nz/ wellington/departments/publichealth/research/bode3/otago076415.html Epidemiological data on stomach cancer used in our model is also available online: https://nzcms-ct-data-explorer.shinyapps.io/version8.

\section{Authors' contributions}

Study conception and design; AT, GK, NN, MM, NW, TB. Statistical analysis; GK. Acquisition of data; AT, NN. Analysis and interpretation of data; AT, GK, NN, MM, NW, TB. Drafting of the manuscript; AT. Critical revision of the manuscript; AT, GK, NN, MM, NW, TB. Obtained funding; TB, NW. All authors read and approved the final manuscript.

\section{Competing interests}

The authors declare that they have no competing interest.

\section{Consent for publication}

Not applicable.

\section{Ethics approval and consent to participate}

No ethics approval was required, as the study uses only secondary data.

Received: 9 January 2016 Accepted: 10 February 2017

Published online: 20 February 2017

\section{References}

1. Plummer M, Franceschi S, Vignat J, Forman D, de Martel C. Global burden of gastric cancer attributable to Helicobacter pylori. International journal of cancer Journal international du cancer. 2015;136(2):487-90.

2. Ford AC, Forman D, Hunt R, Yuan Y, Moayyedi P. Helicobacter pylori eradication for the prevention of gastric neoplasia. The Cochrane Library. 2015;7:CD005583.
3. Fock KM, Katelaris P, Sugano K, Ang TL, Hunt R, Talley NJ, Lam SK, Xiao SD Tan HJ, Wu CY. Second Asia-Pacific consensus guidelines for helicobacter pylori infection. J Gastroenterol Hepatol. 2009;24(10):1587-600.

4. Richard Hunt M, Carlo Fallone M, Sander Veldhuyzan van Zanten M, Phil Sherman M. Canadian Helicobacter Study Group Consensus Conference: Update on the management of Helicobacter pylori-an evidence-based evaluation of six topics relevant to clinical outcomes in patients evaluated for $\mathrm{H}$ pylori infection. Can J Gastroenterol. 2004;18(9):547.

5. International Agency for Research on Cancer, World Health Organization. Helicobacter pylori Eradication as a Strategy for Preventing Gastric Cancer. In: Working Group Report, vol. 8. Lyon: International Agency for Research on Cancer; 2014

6. Ford AC, Forman D, Hunt RH, Yuan Y, Moayyedi P. Helicobacter pylori eradication therapy to prevent gastric cancer in healthy asymptomatic infected individuals: systematic review and meta-analysis of randomised controlled trials. BMJ. 2014;348:93174.

7. Harris RA, Owens DK, Witherell H, Parsonnet J: Helicobacter pylori and Gastric Cancer: What Are the Benefits of Screening Only for the CagA Phenotype of H. pylori? Helicobacter. 1999;4(2):69-75.

8. Parsonnet J, Harris RA, Hack HM, Owens DK. Modelling cost-effectiveness of Helicobacter pylori screening to prevent gastric cancer: a mandate for clinical trials. The Lancet. 1996;348(9021):150-4.

9. Xie F, Luo N, Blackhouse G, Goeree R, Lee HP. Cost-effectiveness analysis of Helicobacter pylori screening in prevention of gastric cancer in Chinese. Int J Technol Assess Health Care. 2008;24(1):87-95.

10. Cheng HC, Wang JD, Chen WY, Chen CW, Chang SC, Sheu BS. Helicobacter pylori test-and-treat program can be cost-effective to prevent gastric cancer in Taiwanese adults: referred to the nationwide reimbursement database. Helicobacter. 2015;20(2):114-24.

11. Xie F, O'Reilly D, Ferrusi IL, Blackhouse G, Bowen JM, Tarride JE, Goeree R. Illustrating economic evaluation of diagnostic technologies: comparing Helicobacter pylori screening strategies in prevention of gastric cancer in Canada. J Am Coll Radiol. 2009;6(5):317-23.

12. Lee YC, Lin JT, Wu HM, Liu TY, Yen MF, Chiu HM, Wang HP, Wu MS, Hsiu-Hsi Chen T. Cost-effectiveness analysis between primary and secondary preventive strategies for gastric cancer. Cancer Epidemiol Biomarkers Prev. 2007;16(5):875-85.

13. Roderick P, Davies R, Raftery J, Crabbe D, Pearce R, Bhandari P, Patel P: The cost-effectiveness of screening for Helicobacter pylori to reduce mortality and morbidity from gastric cancer and peptic ulcer disease: a discrete-event simulation model. Health Technol Assess. 2003;7(6):1-86.

14. Blakely T, Shaw C, Atkinson J, Cunningham R, Sarfati D. Social inequalities or inequities in cancer incidence? Repeated census-cancer cohort studies, New Zealand 1981-1986 to 2001-2004. Cancer causes \& control. 2011;22(9):1307-18.

15. Teng AM, Blakely T, Baker MG, Sarfati D. The contribution of Helicobacter pylori to excess gastric cancer in Indigenous and Pacific men: a birth cohort estimate. Gastric Cancer. 2016:1-4. Accessed July 2015.

16. Fraser A. Treatment for Helicobacter infection in New Zealand: A discussion document. In: Gastroenterology NZSoG: New Zealand Society of Gastroenterology; 2013.

17. Fendrick AM, Chernew ME, Hirth RA, Bloom BS, Bandekar RR, Scheiman JM. Clinical and Economic Effects of Population-Based Helicobacter pylori Screening to Prevent Gastric Cancer. Arch Intern Med. 1999;159:142-8.

18. Mason J, Axon ATR, Forman D, Duffett S, Drummond M, Crocombe W, Feltbower R, Mason S, Brown J, Moayyedi P. The cost-effectiveness of population Helicobacter pylori screening and treatment: a Markov model using economic data from a randomised trial. Aliment Pharmacol Ther. 2002;16:559-68.

19. Yeh JM, Kuntz KM, Ezzati M, Goldie SJ. Exploring the cost-effectiveness of Helicobacter pylori screening to prevent gastric cancer in China in anticipation of clinical trial results. Int J Cancer. 2009;124(1):157-66.

20. Shimoyama T, Oyama T, Matsuzaka M, Danjo K, Nakaji S, Fukuda S. Comparison of a Stool Antigen Test and Serology for the Diagnosis of Helicobacter pylori Infection in Mass Survey. Helicobacter. 2009;14:87-90.

21. Costilla R, Atkinson J, Blakely T. Incoporating Ethnic and Deprivation Variation to Cancer Incidence Estimates over 2006-2026 for ABC-CBA. In: Public Health Monograph, vol. 19. Wellington: University of Otago; 2011. Burden of Disease Epidemiology Equity and Cost-Effectiveness Programme $\left(\mathrm{BODE}^{3}\right)$, vol. Technical Report Number 5. 
22. Forman D, Bray F, Brewster D, Gombe Mbalawa C, Kohler B, Piñeros M, et al. Cancer incidence in five continents. Lyon: International Agency for Research on Cancer; 2013.

23. New Zealand Period Life Tables: 2010-2012. [http://www.stats.govt.nz/ browse_for_stats/health/life_expectancy/NZLifeTables_HOTP10-12.aspx]. Accessed July 2015.

24. Blakely T, Costilla R, Soeberg M. Cancer Excess Mortality Rates Over 2006-2026 for ABC-CBA. Wellington: University of Otago; 2012.

25. Salomon JA, Vos T, Hogan DR. Common values in assessing health outcomes from disease and injury: disability weights measurement study for the Global Burden of Disease Study 2010. Lancet. 2010;380(9859):2129-43.

26. Ministry of Health. Health Loss in New Zealand: A Report from the New Zealand Burden of Diseases, Injuries, and Risk Factors Study, 2006-2016. Wellington: Ministry of Health; 2013.

27. Trendly Beta: Promoting High Performance in Health [http://trendly.co.nz/ Home/DHBIndicatorSummaryReport]. Accessed July 2015.

28. The changing face of Helicobacter pylori testing [http://www.bpac.org.nz/ BT/2014/May/h-pylori.aspx]. Accessed July 2015.

29. Hsiang J, Selvaratnam S, Taylor S, Yeoh J, Tan Y-M, Huang J, Patrick A. Increasing primary antibiotic resistance and ethnic differences in eradication rates of Helicobacter pylori infection in New Zealand - a new look at an old enemy. New Zealand Medical Journal. 2013;126(1384):64-76.

30. Li WQ, Ma JL, Zhang L, Brown LM, Li JY, Shen L, Pan KF, Liu WD, Hu Y, Han ZX et al: Effects of Helicobacter pylori treatment on gastric cancer incidence and mortality in subgroups. J Natl Cancer Inst. 2014, 106(7). Accessed July 2015.

31. PPPs and exchange rates: Purchasing Power Parities for GDP [https://stats. oecd.org/Index.aspx?DataSetCode=SNA_TABLE4\#]. Accessed July 2015

32. Prices and purchasing power parities (PPP): new international comparisons of GDP and consumption based on purchasing power parities for the year 2011 [http://www.oecd.org/std/prices-ppp/ppps-2011-benchmark-year.htm]. Accessed July 2015.

33. Blakely T, Foster R, Wilson N. Public Health Monograph, vol. 30. Wellington: University of Otago; 2012. Burden of Disease Epidemiology Equity and Cost-Effectiveness Programme (BODE $\left.{ }^{3}\right)$.

34. Foster R, Blakely T, Wilson N, O'Dea D. Protocol for Direct Costing of Health Sector Interventions for Economic Modelling (Including Event Pathways). In: Public Health Monograph, vol. 27. Wellington: University of Otago; 2013. Burden of Disease Epidemiology Equity and Cost-Effectiveness Programme (BODE ${ }^{3}$ ).

35. Foster R, Preval N. Costing of pharmaceuticals in New Zealand for health economic studies: backgrounder and protocol for costing. In: Public Health Monograph, vol. 20. Wellington: University of Otago; 2011. Burden of Disease Epidemiology Equity and Cost-Effectiveness Programme $\left(\mathrm{BODE}^{3}\right)$.

36. Brown KA, Khanafer N, Daneman N, Fisman DN. Meta-analysis of antibiotics and the risk of community-associated Clostridium difficile infection. Antimicrob Agents Chemother. 2013;57(5):2326-32.

37. Ford AC, Forman D, Bailey AG, Axon AT, Moayyedi P. A community screening program for Helicobacter pylori saves money: 10-year follow-up of a randomized controlled trial. Gastroenterology. 2005;129(6):1910-7.

38. National Health Committee: Screening to Improve Health in New Zealand: Criteria to assess screening programmes. In. Wellington: Ministry of Health; 2003. https://www.nsu.govt.nz/publications/screening-improve-health-newzealand-criteria-assess-screening-programmes.

39. Herrero R, Park JY, Forman D. The fight against gastric cancer - the IARC Working Group report. Best Pract Res Clin Gastroenterol. 2014;28(6):1107-14.

40. Ford AC, Moayyedi P. Whom should we "test and treat" for Helicobacter pylori? BMJ. 2014;348:g3320.

41. McDonald AM, Sarfati D, Baker MG, Blakely T. Trends in Helicobacter pylori infection among Maori, Pacific, and European Birth cohorts in New Zealand. Helicobacter. 2015;20(2):139-45.

\section{Submit your next manuscript to BioMed Central and we will help you at every step:}

- We accept pre-submission inquiries

- Our selector tool helps you to find the most relevant journal

- We provide round the clock customer support

- Convenient online submission

- Thorough peer review

- Inclusion in PubMed and all major indexing services

- Maximum visibility for your research

Submit your manuscript at www.biomedcentral.com/submit 